\title{
PROCEDIMENTO PARA A AVALIAÇÃO DA QUALIDADE VISUAL PERCEBIDA EM ARTEFATOS PARA PREENSÃO DE LÁPIS
}

\section{PROCEDURE FOR EVALUATING PERCEIVED VISUAL QUALITY OF PENCIL-HOLDING DEVICES}

\author{
Juliana Fonsêca de Queiroz Marcelinoํㅗㄹ Doutoranda em Design \\ Lourival Costa Filho ${ }^{2}$, D.Sc. \\ Laura Bezerra Martins ${ }^{3}$, D. Sc. \\ (1) Universidade Federal de Pernambuco (UFPE) \\ e-mail: julifons@yahoo.com.br \\ (2) Universidade Federal de Pernambuco (UFPE) \\ e-mail: lourivalcosta@yahoo.com \\ (3) Universidade Federal de Pernambuco (UFPE) \\ e-mail: bmartins.laura@gmail.com
}

Palavras-chave: artefatos para preensão do lápis, tecnologia assistiva, qualidade visual percebida.

Este artigo objetiva apresentar o protótipo de um procedimento para a avaliação da qualidade visual percebida, em artefatos para preensão de lápis, projetado para o desenho ou escrita de pessoas com deficiência motora por sequela neurológica, sob a ótica dos especificadores. A Teoria das Facetas foi adotada no desenho do protótipo da ferramenta proposta, que deve ser confirmada ou reformulada, após o teste das hipóteses inicialmente consideradas.

Keywords: pencil-holding devices, assistive technology, perceived visual quality.

This article aims to present a prototype for a procedure for the assessment of perceived visual quality of pencil gripping devices used by children with motor disabilities from the perspective of their specifiers. Facets Theory was adopted in the proposed methodological prototype design, which must be confirmed or reformulated after testing the initially considered hypotheses.

\section{Introdução}

No processo de configuração, o designer deve otimizar as funções de um produto visando satisfazer às necessidades dos futuros usuários.

As informações sobre as necessidades dos futuros usuários, infelizmente, são obtidas de segunda mão e elas muitas vezes são parciais, regidas por critérios práticos ou limitadas aos interesses das empresas produtoras. Em muitos casos, solicita-se ao designer que estabeleça as funções estéticas e simbólicas baseadas em seus estudos ou em sua experiência profissional. Por isso, a configuração de produtos se baseia, na maioria das vezes, em um 


\section{$16^{\circ}$ \\ ERGODESIGN USIHC CINAHPA}

$16^{\circ}$ Ergodesign - Congresso Internacional de Ergonomia e Usabilidade de Interfaces Humano Tecnológica: Produto, Informações Ambientes Construídos e Transporte

$16^{\circ}$ USIHC - Congresso Internacional de Ergonomia e Usabilidade de Interfaces Humano Computador

CINAHPA | 2017 - Congresso Internacional de Ambientes Hipermídia para Aprendizagem. processo de tentativas e erros. Caso o designer, no seu trabalho, tivesse acesso a dados mais objetivos sobre as necessidades estéticas e simbólicas do futuro usuário, ou se tivesse a oportunidade de investigá-las diretamente, poderia então estabelecer os aspectos estéticos dos produtos, segundo critérios racionais (LÖBACH, 2001).

Adiante, na mesma obra, o autor acima citado acrescenta que o processo de desenvolvimento de produtos ocorre quase sempre segundo critérios racionais. Apenas a configuração estética formal se dá pelo "processo criativo", escolhendo-se a configuração ideal entre muitas alternativas geradas. Mas com qual critério?

Quando se trata do Ergodesign, é necessário que o designer - no processo de configuração de um produto - aplique conhecimentos sobre a percepção estética; um processo subjetivo, pois depende da opinião e experiência de cada usuário, sendo também o mais difícil de ser mensurado.

A percepção estética é uma expansão dos conhecimentos sensoriais humanos, e a aceitação ou recusa de um produto depende principalmente do tipo de configuração. Assim, os conhecimentos sobre a qualidade visual percebida em produtos têm cada vez mais importância para o design.

Quando se leva em consideração o tipo de objeto enfocado no estudo aqui apresentado - artefatos para a preensão de lápis, projetado para o desenho ou escrita de pessoas com deficiência motora por sequela neurológica - observa-se, apoiando-se em Bins Ely (2004), ser urgente a atualização de conhecimentos técnicos para projetar produtos que atendam às necessidades específicas dos usuários com restrições, visto que não estão contemplados na formação acadêmica de muitos designers.

Nessa direção, a qualidade visual percebida pode ser um dos fatores associados ao sucesso no uso de um dispositivo assistivo, pois, segundo Kintsch e DePaula (2002), a imagem do produto vai interferir na sua aceitação e na continuidade de uso.

A partir do exposto, este artigo tem como objetivo apresentar o protótipo de um procedimento para a avaliação da qualidade visual percebida, em artefatos para preensão de lápis, projetado para o desenho ou escrita de pessoas com deficiência motora por sequela neurológica, sob a ótica dos especificadores.

Para tal, recorre-se inicialmente à literatura especializada para abordar: (1) o artefato enfocado como tecnologia assistiva; (2) a percepção estética e aspectos estéticos do produto; e (3) a qualidade visual percebida. Depois, apresenta-se também a Teoria das Facetas (TF) e sua aplicação na formulação da estrutura metodológica proposta para a avaliação da qualidade visual percebida em artefatos para preensão de lápis, projetado para o desenho ou escrita de pessoas com deficiência motora por sequela neurológica, sob a ótica dos especialistas especificadores. A escolha deu-se pela facilidade de a TF expressar suposições teóricas, ou seja, hipóteses, de tal forma que se poderá examinar empiricamente a sua validade em pesquisas futuras, haja vista que todo delineamento de facetas define uma pesquisa específica que se resume em uma sentença estruturadora, nesse caso como protótipo de um procedimento, que será apresentado na última seção deste artigo, baseado nos mais significativos elementos configurativos (forma, cor, textura, material) e em dois importantes fatores de constituição da figura do produto (ordem e complexidade).

Cabe destacar a importância desse protótipo de procedimento para a área do Ergodesign de produtos, na medida em que as evidências empíricas encontradas, a partir de sua aplicação, podem contribuir para o desenvolvimento de novos estudos - envolvendo a determinação da função estética do artefato para apreensão do lápis - e, por conseguinte, a melhoria do projeto desse produto.

\section{Considerações Teóricas}

O produto estudado, motivador do estudo realizado e aqui apresentado, foi projetado para o desenho ou escrita de pessoas com deficiência motora por sequela neurológica. Essas pessoas apresentam dificuldades para desempenhar tais atividades devido à alteração em componentes motores como tônus e força muscular, que interferem na função manual, e, por isso, precisam de instrumentos 


\section{$16^{\circ}$ \\ ERGODESIGN USIHC CINAHPA}

adaptados. Para o desempenho funcional dessas atividades, falta, a essas pessoas, o controle do movimento, que, segundo Shumway-Cook e Woollacott (2003), é obtido pelo esforço cooperativo de muitas estruturas cerebrais nos sistemas de percepção e ação.

Os artefatos de preensão do lápis podem ser classificados como produtos de Tecnologia Assistiva, definida como "uma área do conhecimento, de característica interdisciplinar, que engloba produtos, recursos, metodologias, estratégias, práticas e serviços que objetivam promover a funcionalidade, relacionada à atividade e participação de pessoas com deficiência, incapacidades ou mobilidade reduzida, visando a sua autonomia, independência, qualidade de vida e inclusão social" (BRASIL, 2007).

As pesquisas de avaliação dos produtos de tecnologia assistiva se baseiam no conceito de usabilidade, especialmente quanto à efetividade e à eficiência, em relação à execução de tarefas. Para Moraes (2004), a efetividade se refere à extensão em que uma meta ou tarefa foi alcançada, enquanto a eficiência se refere à quantidade de esforço que $\mathrm{o}$ indivíduo investe para atingir sua meta.

A função estética, entretanto, é relacionada por Moraes (2004) à satisfação com que usuários específicos atingem metas específicas, uma vez que se refere ao nível do conforto e de acessibilidade dos usuários ao usar um produto. Sendo, para a autora citada, um aspecto muito importante da usabilidade, pois envolve o sentimento do usuário em relação ao produto.

A ISSO - International Standards Organization, referenciada em Jordan (2000, p.7), define usabilidade como "a efetividade, eficiência e satisfação com que usuários específicos atingem metas específicas em ambientes particulares".

Pode-se, sob esse prisma, ter satisfação com a estética do produto, tendo sido localizados dois trabalhos publicados sobre Tecnologia Assistiva (KINTSCH, 2002; BARBOSA FILHO, 2008), que apontam a estética do produto como importante para o sucesso do produto pelo usuário. $16^{\circ}$ Ergodesign - Congresso Internacional de Ergonomia e Usabilidade de Interfaces Humano Tecnológica: Produto, Informações Ambientes Construídos e Transporte

$16^{\circ}$ USIHC - Congresso Internacional de Ergonomia e Usabilidade de Interfaces Humano Computador

CINAHPA | 2017 - Congresso Internacional de Ambientes Hipermídia para Aprendizagem.

$\mathrm{O}$ foco da maioria das pesquisas em Tecnologia Assistiva, dito antes, limita-se à efetividade e eficiência dos produtos auxiliarem pessoas com deficiência a desempenharem certas atividades.

Foi nesse contexto estratégico que se desenvolveu um estudo com foco nas questões da percepção estética, objetivando apresentar o protótipo de um procedimento para avaliação da qualidade visual percebida em artefatos para preensão do lápis, utilizados por crianças com deficiência motora, sob a ótica de seus especificadores.

Um aspecto essencial da percepção estética é a oferta suficiente de informação. Sendo assim, um produto deve manter o interesse, durante o maior tempo possível, como objeto de percepção estética. Isto é factível através da complexidade agregada à aparência estética. A estrutura da configuração pode levar o usuário a reconhecer constantemente novas relações de ordem, mantendo o interesse sobre o produto (LÖBACH, 2001).

Assim, segundo o mesmo autor e obra, se um produto industrial for demasiado pobre de informação, ele perde sua capacidade de manter a atenção por muito tempo, durante o processo de percepção estética. $\mathrm{O}$ usuário não tem, então, a oportunidade de "desvendá-lo" psiquicamente. Quanto mais níveis de observação um produto industrial oferecer à percepção humana, mais duradora será a sua capacidade de reter a atenção do usuário por meio dessa qualidade estética.

As características estéticas da configuração de um produto são determinadas por seus elementos configurativos, descritos na literatura como portadores da informação estética de um produto. A sua seleção e combinação, pelo designer, definirá a reação que o futuro usuário apresentará frente ao produto. Nessa perspectiva, por meio da ordenação dos elementos configurativos em um produto industrial, a partir dos conhecimentos estéticos, é possível que tais produtos se tornem agradáveis aos sentidos humanos e alcance os efeitos desejados (LÖBACH, 2001).

Esses elementos configurativos (forma, cor, textura da superfície, material) foram considerados como categoria teórica importante para a avaliação da 
$16^{\circ}$ Ergodesign - Congresso Internacional de Ergonomia e Usabilidade de Interfaces Humano Tecnológica: Produto, Informações Ambientes Construídos e Transporte

$16^{\circ}$ USIHC - Congresso Internacional de Ergonomia e Usabilidade de Interfaces Humano Computador CINAHPA

CINAHPA | 2017 - Congresso Internacional de Ambientes Hipermídia para Aprendizagem.

qualidade visual percebida do artefato de preensão do lápis, adiante mais detalhado, quando o protótipo do procedimento para realizar tal avaliação será pormenorizado.

Duas características da figura de um produto industrial - ordem e complexidade - foram tomadas para estudo, por causa de suas relevâncias para o processo de percepção estética e de suas prováveis influências para a qualidade visual percebida. A ordem em um produto industrial é determinada por um pequeno número de elementos configurativos; já a complexidade, em sentido oposto, é determinada por um elevado número de elementos de configuração e por uma grande quantidade de características de ordenamento.

Em relação ao processo de percepção estética, ordem e complexidade dependem entre si de tal forma, que um exclui o outro. Sob esse prisma, um produto industrial com elevada ordem tem uma baixa complexidade, e um produto com alta complexidade tem pouca ordem.

Para a percepção humana, uma ordem elevada significa uma oferta de percepção com baixo conteúdo de informação. Esse tipo de configuração, em consequência, é rapidamente captado com pouco esforço perceptivo, mas tem escassa capacidade de manter a atenção do observador, que pode se aborrecer com a monotonia e desviar a atenção para outras coisas. Isso significa, porém, que a ordem dá uma sensação de segurança. Alta complexidade, para a percepção humana, ao inverso, significa uma oferta de percepção com grande conteúdo de informação. A atenção do observador, em consequência, fica comprometida por mais tempo. A aparência complexa provoca insegurança no observador, que, em parte, pode ser reduzida por meio da observação analítica da estrutura configurativa e o conhecimento de suas relações (LÖBACH, 2001).

A qualidade visual percebida é um constructo psicológico: envolve avaliações subjetivas. Tais avaliações têm referências primárias tanto para o produto industrial como para os sentimentos das pessoas sobre ele. As primeiras são chamadas de julgamentos perceptivos/cognitivos, e as últimas de julgamentos emocionais. Embora a qualidade visual percebida dependa, em parte, dos fatores perceptuais/cognitivos, por definição, é um julgamento emocional e envolve avaliação e sentimentos (NASAR, 1988).

Como o processo de percepção estética está indissociavelmente conectado com os propósitos humanos, a qualidade visual percebida tem sido descrita como produto de dois propósitos humanos universais e fundamentais: "fazer sentido" e "envolvimento" (KAPLAN, 1988). Logo, um produto precisa "fazer sentido" para ser entendido e operado pelo observador/usuário, assim como promover "envolvimento" para chamar sua atenção. Para Nasar (1988), ordem e complexidade desempenham papéis importantes na satisfação desses propósitos humanos.

Para um produto "fazer sentido", precisa de unidade, padronização, organização ou algo que favoreça sua interdependência. Ajudando a compreensão, a ordem - obtida através da redução do número dos elementos configurativos (forma, cor, textura da superfície, material) de um produto industrial - pode reduzir a incerteza e aumentar o tom hedônico (KAPLAN, 1988). Essas relações, segundo Nasar (1988), têm sido consistentemente confirmadas em pesquisas empíricas.

Por definição, pouca complexidade é monótona e fatigante; muita complexidade é caótica e estressante. O nível médio de complexidade parece ser o mais agradável, ou mesmo o ideal. Assim, a relação da complexidade com o tom hedônico (agradabilidade/beleza) tem sido postulada como tendo a forma de ' $U$ ' invertido (BERLYNE, 1972).

A ordem e a complexidade de um produto industrial podem ser manipuladas, levando em conta a quantidade de elementos configurativos nele relacionados. Esses dois fatores foram considerados, juntamente com os elementos configurativos, como categorias hipoteticamente importantes para a avaliação da qualidade visual percebida em artefatos de preensão de lápis, para crianças com deficiência motora, detalhado na aplicação da Teoria das Facetas, no estudo aqui apresentado. 


\section{$16^{\circ}$ \\ ERGODESIGN USIHC CINAHPA}

$16^{\circ}$ Ergodesign - Congresso Internacional de Ergonomia e Usabilidade de Interfaces Humano Tecnológica: Produto, Informações Ambientes Construídos e Transporte

$16^{\circ}$ USIHC - Congresso Internacional de Ergonomia e Usabilidade de Interfaces Humano Computador

CINAHPA | 2017 - Congresso Internacional de Ambientes Hipermídia para Aprendizagem.

\section{Considerações Teórico-Metodológicas}

A Teoria das Facetas (TF), criada por Louis Gutmann durante os anos 1950, foi adotada na formulação do protótipo metodológico proposto para a avaliação da qualidade visual percebida em artefatos para preensão de lápis.

Para Bilsky (2003), a Teoria das Facetas é um procedimento que abrange três estágios diferentes: (1) oferta de princípios sobre como delinear pesquisas para a coleta sistemática dos dados, assim como, igualmente, oferece um marco de referência formal que facilita o desenvolvimento de teorias (metateoria); (2) apresenta os métodos para analisar os dados com um mínimo de restrições estatísticas, adequados às grandes variedades de variáveis; (3) facilidade de expressar suposições teóricas (hipóteses) de tal forma que permita examinar empiricamente sua validade.

De forma resumida, segundo o mesmo autor, diferenciam-se três principais tipos de facetas. $\mathrm{O}$ primeiro tipo refere-se à população amostral que se pretende abordar (background). O segundo tipo contempla o conteúdo das variáveis pesquisadas e, juntamente com a faceta de background, estabelece o domínio da pesquisa. $\mathrm{O}$ terceiro tipo representa o universo de respostas possíveis (racional) em relação ao domínio da pesquisa.

Há três facetas básicas de conteúdo para a avaliação do produto e do ambiente, cada uma representa um componente do objeto de estudo: referente, foco, nível. A faceta de referente expõe os diferentes aspectos que as pessoas se baseiam para realizar suas avaliações; a de foco modula o referente da experiência; e a de nível leva em conta a escala perceptiva, que interfere na avaliação de uso. Essas relações entre os diversos aspectos da experiência das pessoas com um dado produto ou ambiente podem ser sumarizadas através de uma sentença estruturadora, que descreve os componentes físicos e a forma como eles são experienciados (COSTA FILHO, 2014).

A sentença estruturadora menciona as diferentes facetas de interesse científico de modo aditivo, e especifica suas relações mútuas, sendo lidas da esquerda para a direita, aplicando de cada vez um elemento interno de cada faceta, assim, produzirá quantas diferentes combinações existam entre os elementos pertencentes ao campo de interesse.

A Tabela 1 expõe a sentença estruturadora para a avaliação da qualidade visual percebida em artefatos para preensão de lápis; os nomes das facetas de conteúdo e os seus elementos de composição interna. A sentença proposta, cumpre explicar, é uma expressão da qualidade visual percebida para esse tipo de produto industrial.

Tabela 1: sentença estruturadora p/avaliação da qualidade visual percebida em artefatos para preensão de lápis.

\begin{tabular}{|c|c|c|}
\hline \multicolumn{3}{|c|}{ A pessoa $(x)$ avalia que um artefato para preensão de lápis com } \\
\hline $\begin{array}{l}\text { FACETA A } \\
\text { (referente) }\end{array}$ & $\begin{array}{c}\text { FACETA B } \\
\text { (referente) }\end{array}$ & $\begin{array}{c}\text { FACETA C } \\
\text { (foco) }\end{array}$ \\
\hline forma & cor & fator de constituição \\
\hline (A1) solta & (B1) neutra & (C1) ordenado \\
\hline (A2) presa & (B2) viva & $\begin{array}{l}\text { (C) meala complexidade } \\
\text { (C3) alta complexidade }\end{array}$ \\
\hline & racional & \\
\hline & $\begin{array}{l}\text { (1) nada } \\
\text { (2) pouco }\end{array}$ & \\
\hline favorece & $\begin{array}{l}\text { (3) mais ou menos } \\
\text { (4) muito } \\
\text { (5) demais }\end{array}$ & sua qualidade visual percebida \\
\hline
\end{tabular}

Fonte: elaborada pelos autores, com base no estudo realizado.

A população amostral a ser abordada na avaliação proposta deve ser composta pelos principais especificadores do tipo de artefatos enfocados, que trabalham com o usuário direto do produto (crianças com deficiência motora) e até as treinam para o uso adequado desse tipo de produto. Esses profissionais são terapeutas ocupacionais e educadores, encontrados, respectivamente, em centros de Reabilitação e Escolas.

As três facetas de conteúdo, relacionadas com a qualidade visual em artefatos para preensão de lápis, utilizados por crianças com deficiência motora - forma, cor, fator de constituição - foram hipoteticamente considerados relevantes para a avaliação proposta. As duas primeiras - forma e cor - são facetas de referente da experiência e representam atributos do produto (elementos configurativos) que podem ser tomadas para realizar as avaliações. A Faceta $\mathrm{A}$ - forma - teve 


\section{$16^{\circ}$ \\ ERGODESIGN USIHC CINAHPA}

$16^{\circ}$ Ergodesign - Congresso Internacional de Ergonomia e Usabilidade de Interfaces Humano Tecnológica: Produto, Informações Ambientes Construídos e Transporte

$16^{\circ}$ USIHC - Congresso Internacional de Ergonomia e Usabilidade de Interfaces Humano Computador

CINAHPA | 2017 - Congresso Internacional de Ambientes Hipermídia para Aprendizagem. seus componentes internos definidos em relação ao ajuste desse tipo de artefato na mão, quais sejam: (a1) solta ou (a2) presa. A Faceta B - cor - teve seus elementos definidos em relação à saturação no artefato, podendo ser: (b1) neutra; (b2) viva. Os outros dois elementos configurativos, textura e material, embora também importantes, foram desconsiderados como facetas de referente, já que será recomendado o uso de imagens para a coleta de dados, e ambos são difíceis de serem percebidos e avaliados apenas através de imagens. A terceira e última - fator de constituição da figura - é uma faceta de foco, que modula o referente, representando a característica dos elementos configurativos considerados na constituição da figura do artefato enfocado (forma, cor): ordenado, média complexidade, alta complexidade.

Assim, foi considerada uma escala de cinco opções para a avaliação da qualidade visual percebida no produto enfocado, sob o ponto de vista de seus especificadores: (1) nada; (2) pouco; (3) mais ou menos; (4) muito; (5) muitíssimo. Os números entre parêntesis expressam o grau de favorecimento para esse tipo de avaliação aqui proposto.

A sentença estruturadora (Tabela 1) desconsiderou a faceta de nível, uma vez que essa categoria não é variável: o nível de experiência investigado é específico para um determinado tipo de artefato.

Com base na sentença estruturadora para a avaliação da qualidade visual percebida em artefatos para preensão de lápis (Tabela 1), as combinações dos componentes internos das facetas de conteúdo $(\mathrm{A} 2 \mathrm{xB} 2 \mathrm{xC2})$ totalizam 12 diferentes conjuntos ou observações a serem consideradas em uma futura investigação empírica (Figura 1).

A sentença estruturadora proposta para avaliação de artefatos para preensão de lápis, como uma referência inicial (protótipo) do procedimento aqui proposto, é analisada em relação aos resultados empíricos que devem confirmar ou reformular as hipóteses inicialmente estabelecidas. Assim, após os dados serem analisados, têm-se informações suficientes para a construção ou não de uma nova sentença, a ser estruturada como uma consequência direta dos resultados empíricos.
Figura 1: elementos de estímulo para as classificações
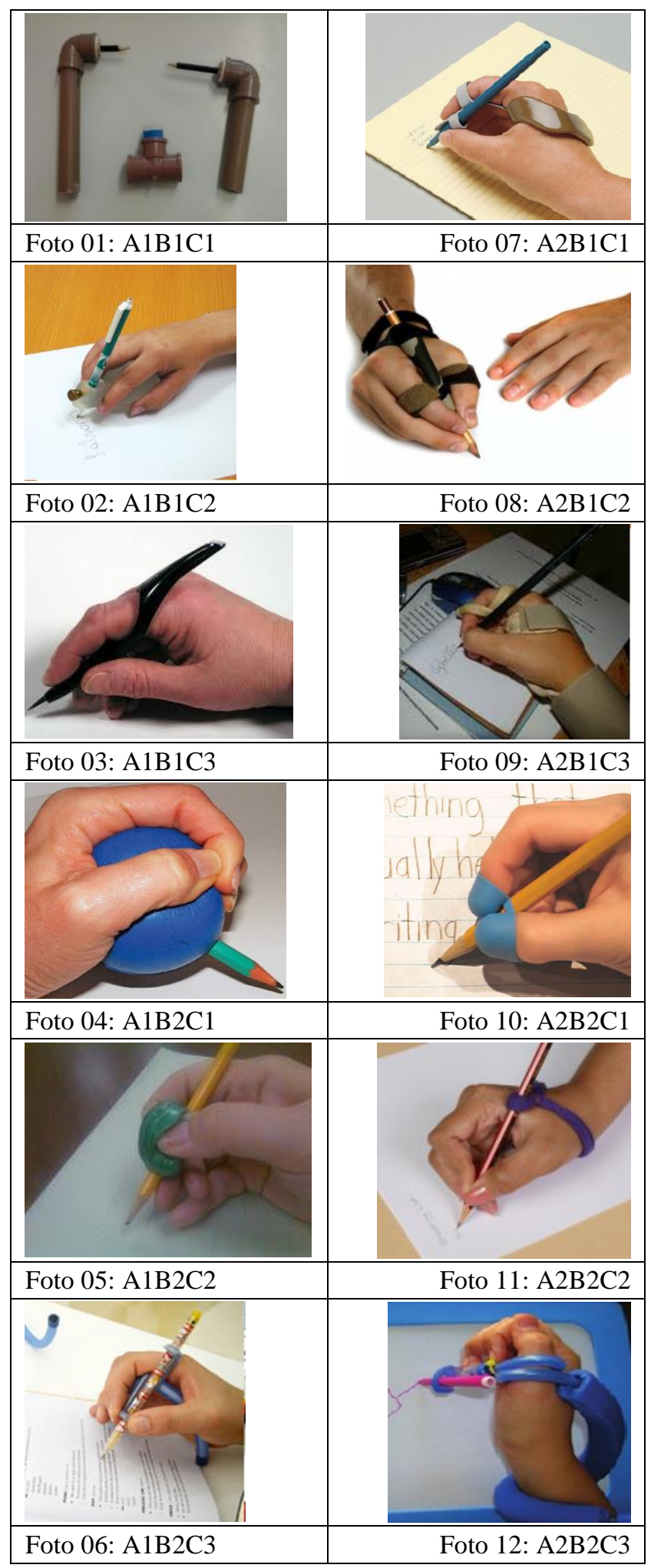

Fonte: www.google.com.br/search?q=preensão+de+lápis 


\section{$16^{\circ}$ \\ ERGODESIGN USIHC CINAHPA}

\section{Considerações Metodológicas}

Nesta seção expõem-se as considerações metodológicas esboçadas para uma futura investigação empírica. A validação do procedimento, todavia, é parte integrante da pesquisa e precisa ser submetido a testes de consistência antes de ser tomado como definitivo.

Para a coleta dos dados, recomenda-se o Sistema de Classificações Múltiplas (CANTER; BROWN; GROAT, 1985), que consiste em solicitar informações aos participantes para classificar os mesmos elementos diversas vezes, com a finalidade de compreender suas ideias e conceitos sobre o objeto de estudo.

O Sistema de Classificações Múltiplas vem sendo muito utilizado para explorar experiências com produtos e ambientes (COSTA FILHO, 2014), e sua aplicabilidade foi ampliada por permitir o uso de ilustrações e outros materiais visuais difíceis de acomodar dentro de outros instrumentos.

A pesquisa adotará como elementos de estímulo, para serem classificados, um conjunto de fotografias de artefatos para preensão do lápis, utilizados por crianças com deficiência motora (Figura 1). A geração desse conjunto, contudo, precisa estar diretamente associada às variáveis desta pesquisa, todas listadas na sentença estruturadora para a avaliação da qualidade visual percebida desse tipo de artefatos (Tabela 1), que estabelece precisamente a relação entre as partes envolvidas, ou seja, a população amostral, o que se pretende avaliar, os referentes e o foco da experiência, além do racional comum às respostas.

Recomenda-se utilizar, junto aos participantes, uma classificação "dirigida". Nesse tipo de classificação, solicita-se que o entrevistado classifique os elementos conforme o critério preestabelecido. Assim, os respondentes devem ser convidados a indicar o grau em que os artefatos apresentados favoreceriam sua especificação para crianças com deficiência motora, e têm a finalidade de verificar a aderência das características hipoteticamente consideradas para a avaliação da qualidade visual percebida desse tipo de produto. $16^{\circ}$ Ergodesign - Congresso Internacional de Ergonomia e Usabilidade de Interfaces Humano Tecnológica: Produto, Informações Ambientes Construídos e Transporte

$16^{\circ}$ USIHC - Congresso Internacional de Ergonomia e Usabilidade de Interfaces Humano Computador

CINAHPA | 2017 - Congresso Internacional de Ambientes Hipermídia para Aprendizagem.

As classificações realizadas devem ser registradas em um formulário especialmente elaborado. Como todos os participantes abordados serão submetidos aos mesmos procedimentos, os dados que variam limitam-se às informações específicas de cada um deles, restritas à primeira página do formulário.

Os dados obtidos na classificação dirigida devem ser interpretados através do procedimento multidimensional Análise da Estrutura de Similaridade (Smilarity Structure Analysis - SSA).

A SSA, segundo Roazzi, Monteiro e Rullo (2009), é um sistema de escalonamento multidimensional concebido para analisar a matriz de correlações entre " $n$ " variáveis representadas graficamente como pontos num espaço euclidiano. O sistema fundamenta-se no princípio da contiguidade que, como tal, traduz as relações de similaridades entre itens, configurado pelas distâncias entre os pontos. Isso significa que a proximidade das variáveis - no espaço multidimensional - é proporcional ao grau de correlação que apresentam. Essas relações de similaridades podem formar regiões de contiguidade que possibilitam verificar se as hipóteses iniciais são transformadas em hipóteses regionais (padrões conhecidos), em relação às quais se espera evidenciar regiões que abarquem aos elementos internos de cada faceta.

A solução da SSA propriamente dita compreende um mapeamento de todos os itens processados para um espaço de dimensionalidade especificada. $\mathrm{Na}$ pesquisa, essa solução compreenderá o processamento das fotografias de vitrinas categorizadas, por cada um dos participantes da amostra, para um espaço bidimensional (diagrama do espaço da SSA).

As análises dos diagramas da SSA podem revelar relações e regras implícitas nos dados obtidos, imperceptíveis nas análises quantitativas usuais. Ao final dos testes, os resultados fornecem bases para a confirmação da sentença estruturadora ou para a construção de uma nova, com a redefinição das hipóteses inicialmente consideradas.

Caso as hipóteses regionais sejam verificadas, revelam aspectos relativamente estáveis do 


\section{$16^{\circ}$ \\ ERGODESIGN USIHC CINAHPA}

$16^{\circ}$ Ergodesign - Congresso Internacional de Ergonomia e Usabilidade de Interfaces Humano Tecnológica: Produto, Informações Ambientes Construídos e Transporte

$16^{\circ}$ USIHC - Congresso Internacional de Ergonomia e Usabilidade de Interfaces Humano Computador

CINAHPA | 2017 - Congresso Internacional de Ambientes Hipermídia para Aprendizagem. conceito investigado, dando-lhe legitimidade, além de confirmar a estrutura interna de conceitos e atributos, possibilitando a percepção de componentes empiricamente verificáveis e da forma como se inter-relacionam (SHYE; ELIZUR; HOFFMAN, 1994).

\section{Conclusão}

Pela via proposta, espera-se aprimorar, no que for possível, os aportes teórico-conceituais relacionados com o objeto de estudo - artefatos para preensão de lápis, utilizados por crianças com deficiência, sob o ponto de vista de seus especificadores -, ampliando sua abrangência analítica, bem como favorecendo o desenvolvimento de projetos balizados pela atualização de evidências estéticas empíricas importantes para a área da acessibilidade.

Os objetivos formulados foram respondidos, em termos gerais, ao apresentar o protótipo de um procedimento para a avaliação da qualidade visual percebida em artefatos para preensão de lápis, utilizados por crianças com deficiência, sob a ótica de seus especificadores.

Ressalta-se ainda, mais especificamente, examinar, com o auxílio dos diagramas da SSA, a aderência das categorias hipoteticamente consideradas para a avaliação da qualidade visual percebida em artefatos para preensão de lápis, utilizados por crianças com deficiência motora, sob a ótica de especificadores, no sentido de validar o protótipo de procedimento desenvolvido e apresentado neste artigo. Esses achados perceptuais/cognitivos poderão confirmar se os elementos configurativos considerados (forma, cor) e a constituição da figura do produto são realmente categorias determinantes para o tipo de avaliação proposta.

Em última análise, os designers poderão fazer bom uso dos dados empíricos produzidos através do procedimento proposto, no sentido de obter bases científicas seguras que embasem suas decisões projetuais. Nessa linha, o protótipo do procedimento proposto poderá, ainda, contribuir para a melhoria da qualidade visual percebida em artefatos para preensão de lápis, utilizados por crianças com deficiência, bem como o Ergodesign desse tipo de produto e, consequentemente, com a qualidade de vida de seus usuários diretos.

\section{Referências}

BARBOSA FILHO, A.N.. Diretrizes para a escolha do produto de tecnologia assistiva. In: OLIVEIRA, A.I.A.; LOURENÇO, J.M.Q.; LOURENÇO, M.G.F. Perspectiva da Tecnologia Assistiva no Brasil: pesquisa e prática. Belém: EDUEPA, 2008, p. 115-120.

BINS ELY, V. H. Acessibilidade Espacial: Condições necessárias para o projeto de ambientes inclusivos. In: MORAES, A. (Org.). Ergonomia do ambiente construído: ambiente urbano, ambiente público, ambiente laboral. Rio de Janeiro: iUsEr, 2004, p. 17-40.

BERLYNE, D. E. Ends and meanings of experimental aesthetics. Canadian Journal of Psychology, n. 26, p. 303-325, 1972.

BILSKY, W.. A Teoria das Facetas: noções básicas. In Estudos de Psicologia, v.8, n.3, 2003. p.357-365.

BRASIL. Comitê de Ajudas Técnicas - CAT. Ata da Reunião VII do Comitê de Ajudas Técnicas. Brasília: Secretaria Especial dos Direitos Humanos da Presidência da República, CORDE/SEDH/PR, dez. 2007. Disponível em: <http://portal.mj.gov.br/ corde/ comite.asp>. Acesso em: 31 jan 2012.

CANTER, D.; BROWN, J.; GROAT, L. A multiple sorting procedure for studying conceptual systems, In: BRENNER, M., BROWN, J., CANTER, D. (Eds). The research interview: uses and approaches. London: Academic Press 79- 114.

COSTA FILHO, L. L. O enfoque da Teoria das Facetas na avaliação de lugares. In: V ENEAC ENCONTRO NACIONAL DO AMBIENTE CONSTRUÍDO E VI SEMINÁRIO NACIONAL DE ACESSIBILIDADE INTEGRAL, 2014. Rio de Janeiro. Anais... Rio de Janeiro: LEUI | PUC-Rio, V ENEAC, 2014. 


\section{$16^{\circ}$ \\ ERGODESIGN USIHC CINAHPA}

KAPLAN, S.. Perception and landscape: conceptions and misconceptions. In: NASAR, Jack. (Ed.). Environmental aesthetics: theory, research, and application. New York: Cambridge University Press, 1988. p. 45-55.

KINTSCH, A. et al. A Framework for the Adoption of Assistive Technology. In: SWAAAC 2002 "Supporting Learning Through Assistive Technology", Winter Park, Colorado, 2002.

JORDAN, P.W. An introduction to usability. London: Taylor\& Francis, 2000.

KINTSCH, A; DE PAULA, R. A Framework for the Adoption of Assistive Technology. In:

SWAAAC 2002 - "Supporting Learning Through Assistive Technology", Winter Park, Colorado, 2002.

LÖBACH, B. Design industrial: bases para a configuração dos produtos industriais. São Paulo: Blucher, 2011.

MORAES, A. Prefácio. In: MORAES, A.. (Org.). $16^{\circ}$ Ergodesign - Congresso Internacional de Ergonomia e Usabilidade de Interfaces Humano Tecnológica: Produto, Informações Ambientes Construídos e Transporte

$16^{\circ}$ USIHC - Congresso Internacional de Ergonomia e Usabilidade de Interfaces Humano Computador

CINAHPA | 2017 - Congresso Internacional de Ambientes Hipermídia para Aprendizagem.

Ergodesign do Ambiente construído e Habitado: Ambiente Urbano, Ambiente Público, Ambiente Laboral. Rio de Janeiro: iUsEr, 2004. p. 7-15.

NASAR, J. L.. The evaluative image of places. In WALSON, W. B., CRAIK, K. H., PRICE, R. H.. (Eds.). Person-environment psychology: New directions and perspectives. New Jersey: Lawrence Erlbaum Associates, Inc., 2000.

ROAZZI, A.; MONTEIRO, C.; RULLO, G.

Residential satisfaction and place attachment: in cross-cultural investigation. In: COHEN, A. (Ed). Facet Theory and scaling: search of structure in behavioral and social sciences. Israel: Rubin R. I. D, 2009.

SHUMWAY-COOK, A.; WOOLLACOTT, M. H. Controle motor: teoria e aplicações práticas. São Paulo: Manole, 2003.

SHYE, S.; ELIZUR, D.; HOFFMAN, M. Introduction to Facet Theory: Content design and intrinsic data analysis in behavioral research. London: Sage, 1994. 